\title{
Evaluation of nitric oxide and some biochemical changes in type 2 diabetic patients in Hilla City
}

\author{
Mufeed Jalil Ewadh, Nibras Yahya Al-Khafaji \\ Babylon University, College of Medicine, Department of Biochemistry, Hilla, Iraq
}

Email address:

mewadh@yahoo.com (M. J. Ewadh)

To cite this article:

Mufeed Jalil Ewadh, Nibras Yahya Al-Khafaji. Evaluation of Nitric Oxide and Some Biochemical Changes in Type 2 Diabetic Patients in Hilla City. Advances in Biochemistry. Vol. 2, No. 4, 2014, pp. 50-54. doi: 10.11648/j.ab.20140204.11

\begin{abstract}
The study was conducted on fifty seven of type 2 diabetic patients and thirty one apparently healthy control subject. Blood samples obtained from all subjects from Marjan Medical City and AL-Hilla Teaching Hospital in Babylon Province. The aim of this study to evaluate the differences of oxidant (nitric oxide and malonyldialdehyde), antioxidant enzyme (superoxide dismutase), trace elements (copper and zinc) and lipid profile in sera of type 2 diabetic patients and the control group. The results of present study reveal a significant increase in nitric oxide, malonyldialdehyde, copper, glucose, total cholesterol, TG, VLDL-cholesterol and LDL-cholesterol concentration in sera of type 2 diabetic patients when compared to those of the control group. Also this study show significant decrease in superoxide dismutase and zinc concentration in sera of type 2 diabetic patients when compared to those of the control group. The study concluded that type 2 diabetic patients is associated with increase oxidative stress. The increase of nitric oxide, malonyldialdehyde and copper concentration and decrease of super oxide dismutase and zinc concentration may contribute in the development of complications in diabetic patients.
\end{abstract}

Keywords: Diabetes Mullets, Nitric Oxide, Malonyldialdehyde, Superoxide Dismutase, Trace Elements

\section{Introduction}

Type 2 Diabetes mellitus is a non autoimmune, heterogeneous and polygenic metabolic diseases in which a person has high blood glucose level (hyperglycemia), because the pancreas does not produce enough insulin and/or cells do not respond to the insulin that is produced [1]. If diabetes is undiagnosed or poorly controlled, it can lead to a state of persistent hyperglycemia, resulting in complications and irreversible damage in a wide range of tissues, most notably the retina (diabetic retinopathy), the kidney glomeruli (diabetic nephropathy), neural tissue (diabetic neuropathy) and blood vessels [2]. DM may be present with characteristic symptoms such as polydipsia (increased thirst), polyuria (frequent urination), polyphagia (increased hunger), blurring of vision, and weight loss. In its most severe forms, ketoacidosis or a non ketotic hyperosmolar state may develop and lead to coma and in the absence of effective treatment, death [3].

DM is accompanied by increased oxidative stress (OS) which plays an important role in the pathogenesis of late vascular complications. The level of OS is a result of balance between the reactive oxygen species (ROS) and reactive nitrogen species (RNS) production and the antioxidative system capacity [4]. In DM, chronic hyperglycemia produces multiple biochemical sequel, and diabetes induced oxidative stress could play a role in the onset and progression of the disease [5]. Persistent hyperglycemia may cause high production of free radicals (FRs) generated by direct autoxidation processes of glucose and by the non enzymatic glycation of proteins with the consequent increased formation of glucose derived advanced glycation end products (AGEs) [6]. The presence of higher glucose or glycated protein concentration enhances lipid peroxidation i.e. malondialdehyde (MDA) and reversely, lipid peroxides may increase the extent of AGEs participating in the chronic vascular complication development [7].

Nitric oxide (NO) is considered as a potent endothelium derived vasodilator that participates in the general homeostasis of the vasculature. The previous studies have demonstrated that the development of diabetic complications in diabetes is closely related to the increased generation of $\mathrm{NO}$ and superoxide anion $\left(\mathrm{O}_{2}{ }^{-}\right)$[8]. $\mathrm{NO}$ is a 
diffusible, liposoluble radical gas produced from Larginine by a family of enzymes known as the nitric oxide synthase (NOS) [9]. NO is highly reactive FR and induces adverse alterations in the structure of proteins, carbohydrates, nucleotides and lipids. It also has a role in cell and tissue destruction and formation of adhesions [10]. It has been reported that diabetic patients have significant defects of antioxidant protections (superoxide dismutase SOD) and generation of oxidants which may play an important role in the etiology of diabetic complications [11].

Trace elements (copper and zinc) are essential nutrients for human beings. They are crucial for the functioning of several enzyme systems and are required in a number of metabolic processes in the body. They are involved in gene expression, RNA and DNA metabolism and cellular immune functions. Thus they are of fundamental importance in living organisms [12].

\subsection{Aims of the Study}

The aims of this study to evaluate the differences of oxidant (nitric oxide and malonyldialdehyde), antioxidant enzyme (super- oxide dismutase), trace elements (copper and zinc) and lipid profile (i.e. total cholesterol, HDLcholesterol, TG, VLDL-cholesterol and LDL-cholesterol) concentration in sera of type 2 diabetic patients and the control group.

\section{Materials and Methods}

\subsection{Materials}

\subsubsection{Subjects}

The study include two groups (patients and control group). All samples were collected from November 2013 till February 2014. The practical side of the study was performed at the laboratory of biochemistry department in College of Medicine / Babylon University. The study was performed on 57 of type 2 diabetic patients. All samples of this group were diagnosed by physicians. They were collected from Marjan Medical City and AL-Hilla Teaching Hospital in Babylon Province. The control group includes 31 apparently healthy subject were collected from my

family, medical staff and relatives. They were free from symptoms and signs of any diseases. Any subject (patients and control group) suffered from problems such as, renal dysfunction, heart diseases, hypertension, infections, drug which affect oxidative stress i.e. antioxidants and drug dependency such as thyroid hormones and glucocorticoid were not include and excluded from the current study.

\subsubsection{Blood Sampling}

Venous blood samples were drawn from patients and control subjects by using disposable syringes $(5 \mathrm{~mL})$ in the sitting position. Subjects will be inquired to come for blood sampling in fasting status. Five milliliters of blood was obtained from each subject by vein puncture and pushed slowly into plain disposable tubes. Blood was allowed to clot at $37^{\circ} \mathrm{C}$ for $10-15$ minutes and then centrifuged at 2000 $\mathrm{Xg}$ for approximately 10-15 minutes then the sera were obtained and divided into five parts and stored at $-20^{\circ} \mathrm{C}$ until analysis.

\subsection{Methods}

Serum NO and SOD concentration are determined by creative diagnostics (USA) ELISA kit. Serum MDA concentration are determined by Guidet B. and Shah S. method [13]. Serum copper and serum zinc concentration are determined by via melano (Italy) spectrophotometric kit. Serum glucose concentration are determined by plasmatic (France) spectrophotometric kit .Serum total cholesterol, TGs and HDL-cholesterol concentration are determined by Biolabo SA (France) spectrophotometric kit. VLDL-cholesterol concentration was calculated by dividing triglycerides value by 2.22 [14]. LDL-cholesterol concentration was calculated by using Friedewald equation [15].

\subsection{Statistical Analysis}

The results were expressed as mean \pm SD. Student's ttest were used for the evaluation of data. Statistical analyses were performed with SPSS version 20.0 software. A $p$ value of $<0.05$ was considered to be statistically significant.

\section{Results}

Table (1). Demographic and Clinical Characteristics of Type 2 Diabetic Patient and Control Group

\begin{tabular}{|c|c|c|c|c|c|}
\hline Parameter & $\begin{array}{l}\text { Control } \\
\text { Mean } \pm \text { SD }\end{array}$ & Range & $\begin{array}{l}\text { patient } \\
\text { Mean } \pm \text { SD }\end{array}$ & Range & $\begin{array}{l}P \\
\text { Value }\end{array}$ \\
\hline No. & 31 & & 57 & & - \\
\hline $\operatorname{Sex} \mathrm{M} / \mathrm{F}$ & $12 / 19$ & & $23 / 34$ & & - \\
\hline Age & $49.29 \pm 5.28$ & $40-57$ & $52.10 \pm 7.71$ & $43-71$ & $>0.05$ \\
\hline Weight & $76.80 \pm 14.46$ & $48-104$ & $84.44 \pm 14.32$ & $55-123$ & $<0.05$ \\
\hline Height & $1.69 \pm 0.09$ & $1.49-1.85$ & $1.68 \pm 0.09$ & $1.51-1.81$ & $>0.05$ \\
\hline BMI & $26.70 \pm 4.27$ & $18.71-34.89$ & $29.47 \pm 3.49$ & $19.66-37.96$ & $<0.01$ \\
\hline Duration of disease & - & & $7.93 \pm 4.59$ & $2-18$ & - \\
\hline
\end{tabular}

The demographic and clinical characteristics of the study groups are shown in table (1). It include number, sex, age, weight, height, body mass index (BMI) of both type 2 diabetic patients and control group were tabulated and 
duration of disease for type 2 diabetic patients also tabulated. The results in table (1) show significant increase ( $\mathrm{p}<0.05$ and $\mathrm{p}<0.01$ ) in BMI and weight of type 2 diabetic patients when compared to those of the control group while there are no significant differences $(p>0.05)$ in age and height of type 2 diabetic patients when compared to those of the control group.

The results of present study reveal a significant increase $(\mathrm{p}<0.001)$ in glucose, total cholesterol, TGs, VLDLcholesterol and significant increase $(\mathrm{p}<0.01)$ in LDLcholesterol concentration in sera of type 2 diabetic patients when compared to those of the control group. While the HDL-cholesterol concentration was found to be non significantly decrease $(p>0.05)$ in sera of type 2 diabetic patients when compared to those of the control group as shown in table (2).

NO, MDA and copper concentration were found to be significantly increased $(\mathrm{p}<0.001)$ in sera of type 2 diabetic patients when compared to those of the control group. Also this study show significant decrease $(p<0.001)$ in SOD and zinc concentration in sera of type 2 diabetic patients when compared to those of the control group as shown in table (3).

Table (2). Mean Fasting Serum Glucose, Total Cholesterol, HDLCholesterol, TGs, VLDL-Cholesterol and LDL-Cholesterol Concentration in Type 2 Diabetic Patients and Control Group

\begin{tabular}{lllll}
\hline $\begin{array}{l}\text { Parameter } \\
(\mathbf{m m o l} / \mathbf{L})\end{array}$ & Subjects & Mean \pm SD & Range & P-value \\
\hline Glucose & Control & $4.89 \pm 0.64$ & $3.3-5.9$ & $<0.001$ \\
Total & patient & $9.72 \pm 2.99$ & $7.2-18.6$ & \\
Cholesterol & Control & $4.17 \pm 0.69$ & $2.66-5.30$ & $<0.001$ \\
HDL & Cotient & $4.97 \pm 0.90$ & $3.81-6.89$ & \\
Cholesterol & patient & $1.08 \pm 0.26$ & $0.58-1.79$ & $>0.05$ \\
Triglycerides & Control & $1.14 \pm 0.24$ & $0.52-1.46$ & \\
VLDL & patient & $1.78 \pm 0.90$ & $0.56-1.89$ & $<0.001$ \\
Cholesterol & Control & $0.51 \pm 0.16$ & $0.25-0.85$ & \\
LDL & patient & $0.80 \pm 0.40$ & $0.25-1.78$ & $<0.001$ \\
Cholesterol & Control & $2.57 \pm 0.66$ & $1.16-3.81$ & $<0.01$ \\
\hline
\end{tabular}

Table (3). Mean Fasting Serum Nitric Oxide (NO), Super Oxide Dismutase (SOD), Malondialdehyde (MDA), Copper and Zinc Concentration in Type 2 Diabetic Patients and Control Group

\begin{tabular}{lllll}
\hline Parameter & Subjects & Mean \pm SD & Range & P-value \\
\hline NO & Control & $41.27 \pm 9.72$ & $24.52-63.57$ & $<0.001$ \\
$(\mathrm{nmol} / \mathrm{mL})$ & patient & $54.13 \pm 11.04$ & $33.62-82.17$ & \\
$\mathrm{SOD}$ & Control & $3.38 \pm 1.46$ & $1.10-7.24$ & $<0.001$ \\
$(\mathrm{ng} / \mathrm{mL})$ & patient & $1.64 \pm 0.78$ & $0.31-3.59$ & \\
$\mathrm{MDA}$ & Control & $1.81 \pm 0.57$ & $0.63-3.12$ & $<0.001$ \\
$(\mu \mathrm{mol} / \mathrm{L})$ & patient & $5.21 \pm 2.06$ & $1.75-10.2$ & \\
$\mathrm{Copper}$ & Control & $1.56 \pm 0.31$ & $0.92-2.26$ & $<0.001$ \\
$(\mu \mathrm{mol} / \mathrm{L})$ & patient & $1.96 \pm 0.50$ & $1.21-3.15$ & \\
Zinc & Control & $12.28 \pm 1.19$ & $8.53-14.12$ & $<0.001$ \\
$(\mu \mathrm{mol} / \mathrm{L})$ & patient & $9.66 \pm 1.54$ & $6.85-12.89$ & \\
\hline
\end{tabular}

\section{Discussion}

The increase of NO level in type 2 diabetic patients of the present study might be attributed to the activation of the inducible isoforms of NOS. In type 2 diabetes, there is a high FR load, which is associated with the hyperglycemia. The elevated glucose binds to proteins, glycating them, and leads to the formation of AGEs and many FRs [16]. AGEs are associated with tissue damage and aging [17]. Once AGEs are formed they bind to their cell surface receptors termed RAGE to endothelial cells and macrophages, resulting in the activation of postreceptor signaling, generation of intracellular ROS and the activation of gene expression. Exposure of endothelial cells to AGEs activates tumor necrosis factor alpha, increases adhesion molecule (including vascular cell adhesion molecule-1) production and iNOS activity [18].

Inducible NOS, is induced by inflammatory cytokines such as interleukin-1 or tumor necrosis factor alpha in macrophages and many other cell types [19]. NO overproduction through Inducible NOS induction in inflammatory conditions appears to inhibit insulin metabolic actions which lead to insulin resistance [20]. This result are in agreement with Sarita A., et al. [21] study which show a significant increase in NO concentration in type 2 diabetic patients when compared with control group.

In the present study, the SOD concentration was significantly decreased in diabetic patients. The decrease of SOD concentration might be attributed to the hyperglycemia activates various biochemical pathways such as glucose autoxidation and non enzymatic glycation of proteins, which in turn overproduction of oxidants like $\mathrm{O}_{2}{ }^{\circ}$ - and $\mathrm{OH}^{\circ}$ as well as $\mathrm{H}_{2} \mathrm{O}_{2}$, the increase of glycosylated SOD that leads to the inactivation of this enzyme [22]. The results of the present study are in agreement with Ahmed A., et al. [23] study which show a significant decrease in SOD concentration in type 2 diabetic patients when compared with control group.

In the present study type 2 diabetic patients group show statistically significant increase in serum MDA level. The most probable causes for the increased MDA level in DM are abnormal lipid metabolism in the type 2 diabetic patients which lead to increase level of lipid, lipoprotein and MDA. Also, the increase MDA may be due to the increased glycation of protein in DM. The glycated protein might themselves act as a source of FRs which increase MDA [24, 25, 26]. The results of the present study are in agreement with Madhikarmi N., et al. [27] study which show a significant increase in MDA concentration in type 2 diabetic patients when compared with control group.

The increase in copper level in patients with type 2 diabetic patients might be attributed to hyperglycaemia, which stimulates glycation and causes release of copper ions from copper binding sites of proteins. The release of copper ions into blood further accelerates the OS [28]. The results of the present study are in agreement with Mohan L., et al. [29] study which show a significant increase in serum copper concentration in type 2 diabetic patients when compared with control group.

Imbalances in zinc homeostasis with reduced plasmatic levels can determine deficiencies of beta pancreatic cells to 
produce and secrete insulin [30]. Zinc ions are involved in the neutralization of FRs and there is increasing evidence supporting the role of zinc as an antioxidant that could protect insulin and cells from being attacked by FRs [31]. Zinc homeostasis is disturbed in patients with DM. The urinary elimination of zinc is increased (hyperglycemia may affect the tubular transport of zinc) and intestinal absorption is decreased in patients with DM [32]. The results of the present study are in agreement with Olaniyan O., et al. [33] study which show a significant decrease in zinc concentration in type 2 diabetic patients when compared with control group.

\section{Conclusions}

The study concluded that type 2 diabetic patients is associated with increase OS. The increase of NO, MDA production and decrease of SOD concentration may contribute in the development of complications in diabetic patients. Oxidative modification of lipoproteins, particularly LDL, may be at least one cause of vascular complications of DM. The impaired trace element metabolism of the present work may have a role in the pathogenesis and progression of DM where the increase of copper and decrease of zinc concentration may disturb the antioxidants and enhance the lipid peroxidation.

\section{References}

[1] Shaikh M., Devrajani B., Shaikh., et al.( 2012): Plasma homocysteine level in patients with diabetes mellitus. World Applied Sciences Journal. 16 (9): 1269-1273.

[2] Wolfs M., Hofer., Wijmenga C., et al.( 2009): Type 2 diabetes mellitus: new genetic insights will lead to new therapeutics. Current Genomics.; 10: 110-118.

[3] Power A., Fauci A., Kasper D., et al. (2007): Diabetes mellitus. Harrison's principle of medicine.16th edit. 14 (323): 2152-2158.

[4] Baynes J. (1991): Role of oxidative stress in development of complications in diabetes. Diabet.; 40: 405-412.

[5] Giugliano D., Ceriello A. and Paolisso G. (1996): Oxidative stress and diabetic vascular complications. Diabet. Care.; 19: 257-267.

[6] Obrosova I., Van Hysen C., Fathallah, L., et al. (2002): An aldose reductase inhibitor reverses early diabetes-induced changes in peripheral nerve function, metabolism and antioxidative defense. FASEB J.; 16: 123-125.

[7] Skrha J., Sindelka G., Kvasnic'ka J., et al. (1999): Insulin action and fibrinolysis influenced by vitamin $\mathrm{E}$ in obese Type 2 diabetes mellitus Prague, Czech Republic, Diabet. Res. Clin. Pract.; 44: 27-33.

[8] Paterson J., Pettegrew A., Dominiczak M., et al. (1991): Screening for hyperlipidaemia in diabetes mellitus. Relation to glycemic control. Ann Clin Biochem.; 28: 254-258.

[9] Alderton K., Cooper E. and Knowles G. (2001): Nitric oxide synthases: structure, function and inhibition. Biochem $\mathrm{J}$. 357: 593-615.

[10] 10. Dong M., Shi Y., Cheng Q., et al. (2001): Increased nitric oxide in peritoneal fluid from women with idiopathic infertility and endometriosis .J Reprod. Med. 46: 887-891.

[11] Opara E. (2002): Oxidative stress, micronutrients, diabetes mellitus and its complications. J R Soc Health. 122 (1): 2834.

[12] Khanna R., Kumar R., Asthana R., et al. (2009): Role of trace elements and antioxidants in free radical mediated injury in neonates. MASAUM Journal of Basic and Applied Sciences. 3 (1): 543-547.

[13] Guidet B. and Shah S. (1989): Enhanced in vivo $\mathrm{H}_{2} \mathrm{O}_{2}$ generation by rat kidney in glycerol induced renal failure . American journal of physiology. 1257: 440-444.

[14] Godkar P. (1994) :Textbook of Medical Technology, Clinical Biochemistry; Principles and Practice, Bhalani publishing house, Bombay. India. 223-225.

[15] Carl A. and Edward R. (2006): Tietz text book of clinical Biochemistery and Molecular Diagnostics 4th ed. 948.

[16] Keenoy B., Vertommen J., et al. (2001): Divergent effects of different oxidants on glutathione homeostasis and protein damage in erythrocytes from diabetic patients: effects of high glucose. Molecular and Cellular Biochemistry. 225: $59-73$.

[17] Wautier J. and Schmidt A. (2004): Protein glycation: a firm link to endothelial cell dysfunction. Circulation Research. 95: $233-238$.

[18] Maria M., Maria G., Corina M., et al. (2007): The source and the targets of oxidative stress in the etiology of diabetic complication. Romanian J. Biophys. 17 (2): 63-84.

[19] Beck K., Eberhardt W., Frank S., et al. (1999): Inducible NO synthase: role in cellular signaling. Journal of Experimental Biology. 202: 645-653.

[20] Perreault M. and Marette A. (2001): Targeted disruption of inducible nitric oxide synthase protects against obesitylinked insulin resistance in muscle. Nat Med. 7: 1138-1143.

[21] Sarita A., Anita D., Adinath N., et al. (2014): The levels of oxidative stress and antioxidants in diabetes mellitus before and after diabetic treatment with or without antioxidants. Journal of Basic and Applied Medical Research. 3 (2):455460.

[22] Mosaad A. and Abd-Allah Y. (2004) Evaluation of some biochemical changes in diabetic patients. Clinica Chimica Acta.; 346: 161-170.

[23] Ahmed A., Yousef A., Sanaa O. et al. (2013): Molecular and biochemical study of superoxide dismutase gene polymorphisms in Egyptian patients with type 2 diabetes mellitus with and without retinopathy. British Journal of Medicine and Medical Research. 3 (4): 1258-1270.

[24] Suryawanshi N., Bhutey A., Nagdeote A., et al. (2006): Study of lipid peroxide and lipid profile in diabetes mellitus. Indian Journal of Clinical Biochemistry. 21 (1): 126-130.

[25] Mahboob M., Rahman M. and Grover P. (2005): Serum lipid peroxidation and antioxidant enzyme levels in male and female diabetic patients. Singapore Med J. 46: 322-324. 
[26] Nacítarhan S., Ozben T. and Tuncer N. (1995): Serum and urine malondialdehyde levels in NIDDM patients with and without hyperlipidaemia. Free Radic Biol Med. 19: 893-896.

[27] Madhikarmi N., Murthy K., Rajagopal G., et al. (2013): Lipid peroxidation and antioxidant status in patients with type 2 diabetes in relation to obesity in Pokhara - Nepal. Journal of Diabetology. 1 (3): 1-8.

[28] Supriya, Shrabani M., Venkata B., et al. (2013): Evaluation of serum copper, magnesium and glycated hemoglobin in type 2 diabetes mellitus. Asian J Pharm Clin Res. 6 (2): 188-190.

[29] Mohan L., Sudha K., Beena V., et al. (2013): Influence of modified levels of plasma magnesium, $\mathrm{Cu}, \mathrm{Zn}$ and iron levels on thiols and protein status in diabetes mellitus and diabetic retinopathy. International Journal of Analytical, Pharmaceutical and Biomedical Sciences. 2 (1): 67-72.
[30] Tang X. and Shay N. (2001): Zinc has an insulin-like effect on glucose transport mediated by phosphoinositol-3 kinase and Akt in 3T3-L1 fibroblasts and adipocytes. Journal of Nutrition. 131: 1414-1420.

[31] Faure P., Lafond J., Coudray C., ., et al. (1994): Zinc prevents the structural and functional properties of free radical treated-insulin. Biochim Biophys Acta. 1209 (2): 260-264.

[32] Chausmer A. (1998): Zinc, insulin and diabetes. J. Am. Coll. Nutr. 17: 109-14.

[33] Olaniyan O., Awonuga M., Ajetunmobi A., et al. (2012): Serum copper and zinc levels in Nigerian type 2 diabetic patients African Journal of Diabetes Medicine. 20 (2): 36-38. 